Abstract P216 Table 1 Multivariate analysis of predictive factors significantly associated in univariate analysis with patient or carer PM

\begin{tabular}{|c|c|c|c|c|}
\hline & Patient PM cases $(n=39)$ & Patient PM non-cases $(n=70)$ & Odds ratio $(95 \% \mathrm{Cl})$ & Significance \\
\hline \multicolumn{5}{|l|}{ Carer PM cases, n (\%) } \\
\hline Y & $17(15.6)$ & $13(11.9)$ & $3.667(0.916-14.680)$ & 0.066 \\
\hline $\mathrm{N}$ & $22(20.2)$ & $57(52.3)$ & & \\
\hline \multicolumn{5}{|l|}{ Patient gender, $\mathrm{n}(\%)$} \\
\hline M & $24(22.0)$ & $42(38.5)$ & $0.728(0.194-2.740)$ & 0.639 \\
\hline $\mathrm{F}$ & $15(13.8)$ & $28(25.7)$ & & \\
\hline No. of exacerbations at home, median (IQR) & $3.5(2-6)$ & $2(0-3)$ & $1.313(1.006-1.713)$ & $0.045^{*}$ \\
\hline CRQ dyspnoea score, median (IQR) & $1.8(1.6-2.6)$ & $2.8(1.8-4)$ & $1.227(0.628-2.398)$ & 0.549 \\
\hline CRQ fatigue score, median (IQR) & $2.5(2-3)$ & $3.75(3-4.5)$ & $0.392(0.173-0.889)$ & $0.025^{*}$ \\
\hline CRQ mastery score, median (IQR) & $3.25(2.25-3.75)$ & $4.75(4.25-5.5)$ & $0.264(0.129-0.539)$ & $0.000^{*}$ \\
\hline \multirow[t]{2}{*}{ No. of patient physical co-morbidities, median (IQR) } & $4(3-6)$ & $4(2-5)$ & $0.832(0.577-1.201)$ & 0.326 \\
\hline & Carer PM cases $(n=30)$ & Carer PM non-cases $(n=79)$ & Odds ratio $(95 \% \mathrm{Cl})$ & Significance \\
\hline \multicolumn{5}{|l|}{ Patient PM cases, n (\%) } \\
\hline Y & $17(15.6)$ & $22(20.2)$ & $3.869(1.070-13.990)$ & $0.039^{*}$ \\
\hline $\mathrm{N}$ & $13(11.9)$ & $57(52.3)$ & & \\
\hline \multicolumn{5}{|l|}{ Carer gender, $\mathrm{n}(\%)$} \\
\hline M & $2(1.8)$ & $29(26.6)$ & $6.180(1.167-32.712)$ & $0.032^{*}$ \\
\hline $\mathrm{F}$ & $28(25.7)$ & $50(45.9)$ & & \\
\hline \multicolumn{5}{|l|}{ Lives with patient, $\mathrm{n}(\%)$} \\
\hline Y & $24(22.4)$ & $71(66.4)$ & $1.883(0.438-8.100)$ & 0.395 \\
\hline $\mathrm{N}$ & $6(5.6)$ & $6(5.6)$ & & \\
\hline Duration of caring in years, median (IQR) & $3.5(2-12)$ & $7(4-13)$ & $0.964(0.903-1.030)$ & 0.278 \\
\hline Hours of caring, median (IQR) ${ }^{\mathrm{a}}$ & $3(2-3.5)$ & $3(2-4)$ & $0.859(0.420-1.755)$ & 0.676 \\
\hline No. of exacerbations at home, median (IQR) & $3(1.5-5.5)$ & $2(0-3.75)$ & $1.048(0.880-1.247)$ & 0.599 \\
\hline No. of carer physical co-morbidities, median (IQR) & $1(1-2)$ & $1(0-2)$ & $1.184(0.769-1.825)$ & 0.443 \\
\hline
\end{tabular}

(a) $1=<1 \mathrm{~h} /$ week, $2=1-19 \mathrm{~h} /$ week, $3=20-49 \mathrm{~h} /$ week, $4=>50 \mathrm{~h} /$ week.

continual focus on the challenge of prognosis and unpredictability of trajectories as barriers to meeting needs, (2) Change targets to incentivise person-centred care within existing services, (3) Enable identification and response to patient support needs (through evidence-based tools and approaches), (4) Identify and support patients' informal carers (through evidence-based tools and approaches), (5) Identify and respond to psychological morbidity in patients and informal carers identify and respond to psychological morbidity, (6) Change societal attitudes and understandings of COPD, breathlessness, palliative care and informal carer support. The recommendations are underpinned by action points to enable delivery. The recommendations garnered significant support from stakeholders, with caution regarding ease of implementation which varied by recommendation.

Conclusion These six inter-related recommendations, and supporting action points, could inform a new framework for care and support in advanced COPD likely to have resonance for those living with other advanced non-malignant long term conditions, and for clinicians striving to support them.

\section{P218 THE DEVELOPMENT AND PSYCHOMETRIC VALIDATION OF THE EARLY MORNING SYMPTOMS OF COPD INSTRUMENT (EMSCI)}

${ }^{1} \mathrm{~A}$ Hareendran, ${ }^{1} \mathrm{E}$ Zaiser, ${ }^{2} \mathrm{~B}$ Make, ${ }^{3} \mathrm{E}$ Garcia Gil. ${ }^{1}$ Evidera, London, UK; ${ }^{2}$ National Jewish Health, Denver, USA; ${ }^{3}$ Astra-Zeneca, London, UK

\subsection{6/thoraxjnl-2016-209333.361}

Introduction In patients with Chronic Obstructive Pulmonary Disease (COPD), symptoms in the early morning have been reported as being the most troublesome and can negatively impact quality of life. This abstract summarises the development and psychometric testing of the Early Morning Symptoms of COPD Instrument (EMSCI) designed to collect data to evaluate COPD patients' experiences early in the morning.

Methods Following a literature review and clinical expert interviews, four focus groups were conducted to identify initial concepts and develop draft items for the EMSCI. One-on-one cognitive debriefing interviews were conducted with 10 COPD patients to confirm item readability, and comprehensiveness. Data from a clinical trial [AUGMENT] in COPD patients $(\mathrm{N}=1663)$ was used for item analyses to inform item-reduction and scoring; and to evaluate psychometric properties. Test-retest reliability was assessed using intra-class coefficient (ICC). Correlations with baseline assessments including the SGRQ, E-RS, and FEV1 were used to evaluate concurrent validity.

Results Focus group participants $(n=27$, mean age $=68.1 \mathrm{y}$ ) reported mucus/phlegm (80\%), shortness of breath $(52 \%)$, coughing (48\%), tightness in chest (24\%), wheezing $(8 \%)$ and chest congestion $(8 \%)$ as the most common early morning symptoms. Limitations to activities and rescue medication use in the early morning were reported by $56 \%$ and $24 \%$ respectively. Cognitive interviews of early versions of the EMSCI suggested the items were comprehensive, relevant and interpreted as intended. Analyses of EMSCI data collected in the Phase 3 trial confirmed a one-factor structure for the symptom severity items. Reliability was confirmed for the 6-item symptom severity (ICC $=0.84$ ), overall symptom severity $(\mathrm{ICC}=0.84)$, activity limitation $(\mathrm{ICC}=0.85)$, and rescue medication $(\mathrm{ICC}=0.62)$ scores. Concurrent validity (Table 1 ) was supported by positive correlations with both the SGRQ and the E-RS scores. 
Conclusions The EMSCI is a reliable and valid instrument that was developed based on patients' experiences to evaluate early morning symptoms and impacts of COPD. It is available to be used for clinical decision making and as a clinical study endpoint for the evaluation of new treatments.

\begin{tabular}{|c|c|c|c|c|}
\hline & $\begin{array}{l}\text { Six-item } \\
\text { Symptom } \\
\text { Summary Score }^{3}\end{array}$ & $\begin{array}{l}\text { Overall Early } \\
\text { Morning Symptoms } \\
\text { Severity }{ }^{4}\end{array}$ & $\begin{array}{l}\text { Activity } \\
\text { Limitation }\end{array}$ & $\begin{array}{l}\text { Early Morning } \\
\text { Puffs of Rescue } \\
\text { Medication }\end{array}$ \\
\hline $\begin{array}{l}\text { SGRQ } \\
\text { total score }\end{array}$ & $0.59^{\star \star \star}$ & $0.56^{\star \star \star *}$ & $0.64^{\star \star \star}$ & $0.33^{\star \star \star *}$ \\
\hline $\begin{array}{l}\text { SGRQ } \\
\text { symptoms } \\
\text { score }\end{array}$ & $0.67^{* \star \star}$ & $0.58^{\star \star \star}$ & $0.52^{\star \star *}$ & $0.33^{\star \star \star *}$ \\
\hline $\begin{array}{l}\text { SGRQ } \\
\text { impacts } \\
\text { score }\end{array}$ & $0.54^{\star \star \star}$ & $0.52^{\star \star \star}$ & $0.60^{\star \star \star}$ & $0.32^{\star \star \star}$ \\
\hline $\begin{array}{l}\text { E-RS total } \\
\text { score }\end{array}$ & $0.83^{\star \star \star}$ & $0.80^{\star \star \star}$ & $0.73^{\star \star \star \star}$ & $0.35^{\star \star \star}$ \\
\hline $\begin{array}{l}\mathrm{FEV}_{1} \\
\text { (trough) }^{2}\end{array}$ & -.04 & -.10 & $-.13^{* *}$ & -.13 \\
\hline
\end{tabular}

1 Spearman rank order correlation coefficients: ${ }^{* * *} \mathrm{P}<0.0001$, ${ }^{* *} \mathrm{P}<0.001,{ }^{*} \mathrm{P}<0.05$

${ }^{2}$ Morning pre-dose value

${ }^{3}$ Average score of six symptoms (Cough, Wheezing, Shortness of breath, Tightness in your chest, Chest congestion, Difficulty bringing up phlegm)

${ }^{4}$ Single-item measuring overall early morning COPD symptom severity

$\mathrm{E}-\mathrm{RS}=$ Evaluating Respiratory Symptoms in COPD; $\mathrm{FEV}_{1}=$ forced expiratory volume in 1

second; SGRQ = St. George's Respiratory Questionnaire

\section{P219 EVALUATION OF INDIVIDUAL ACTIVITY DESCRIPTORS OF THE MRC DYSPNOEA SCALE: DO THEY ADD UP?}

1J Yorke, 'M Khan, '1 Vestbo, 'D Singh, ${ }^{2} \mathrm{PJ}$ Jones. 'University of Manchester, Manchester, UK: ${ }^{2}$ St Georges Medical School, London, UK

\subsection{6/thoraxjnl-2016-209333.362}

Introduction The MRC dyspnoea scale consists of five grades that contain of a description of more than one activity. The comparability of these components is not known. This study aimed to examine the performance of individual descriptions of each MRC grade.

Methods Phase I: cognitive debriefing with COPD patients was conducted to elicit their understanding of each activity (10 items) of the five MRC grades. Phase II: COPD patients completed the MRC scale (grades 1-4) and a MRC-Exploded (MRC-Ex) version consisting of 10-items, each representing one MRC activity. Each item used a 4-point response scale (0 'not at all' to 4 'all of the time'). Rasch analysis was used to assess the pattern of MRCEx item severity (logit) to assess the appropriateness of combining individual activity descriptors into single MRC grades.

Results 36 patients participated in cognitive debriefing. Key issues identified: MRC 1: unclear what constituted 'strenuous exercise' and does not represent mild severity and MRC 5: 'too breathless to leave the house' viewed as "much worse than being breathless with dressing”. 203 patients completed Phase II (mean age 64.7 SD 7.5 years, GOLD: 1:14\% 2:41\% 3:25\% 4:7\%). The easiest item to affirm was 'walking up a slight hill' (logit -2.76 ) and "too breathless to leave the house" was the most difficult (logit 3.42) (Table 1). MRC components in grade 5 are not of equivalent severity - at least 2 logits apart.
Conclusions This study highlight the importance of context when using the MRC. Grade 1 "strenuous exercise" is unlikely to yield a reliable response from patients diagnosed with COPD. Secondly, if data collection is taking place outside of the home then it is pointless to ask respondents if they are too breathless to leave the house; on the other hand, if studying patients who may require palliative care services, that might well be relevant. For contexts where it would be relevant, we suggest separating Grade 5 components: "leave the house" and "dressing/undressing".

\begin{tabular}{lll}
$\begin{array}{l}\text { Abstract P219 Table } \\
\text { component }\end{array}$ & \multicolumn{2}{l}{ Logit (severity) location for each MRC } \\
\hline MRC Grade & Item & Severity (logit) \\
\hline $\mathbf{2}$ & slight hill & -2.76 \\
$\mathbf{2}$ & Hurrying on flat & -2.519 \\
$\mathbf{1}$ & Strenuous exercise & -1.389 \\
3 & same age & -0.847 \\
$\mathbf{3}$ & own pace & 0.043 \\
4 & 100metres & 0.427 \\
$\mathbf{4}$ & few minutes & 1.051 \\
$\mathbf{5}$ & dressing & 1.1 \\
$\mathbf{5}$ & undressing & 1.472 \\
$\mathbf{5}$ & leave house & 3.422 \\
\hline
\end{tabular}

\section{P220 DETERMINANTS OF INHALER ADHERENCE IN A COPD POPULATION}

II Sulaiman, 'B Cushen, ' $G$ Greene, 'I Seheult, 'D Seow, ${ }^{1} \mathrm{~F}$ Rawat, ${ }^{1} \mathrm{E}$ MacHale, ${ }^{1} \mathrm{MC}$ Mokoka, ${ }^{1} \mathrm{CN}$ Moran, ${ }^{1} \mathrm{~A}$ Sartinin-Bhreathnach, ${ }^{1} \mathrm{~S}$ Tappuni, ${ }^{1} \mathrm{P}$ MacHale, ${ }^{1} \mathrm{~B}$ Deering, ${ }^{1} \mathrm{M}$ Jackson, ${ }^{1} \mathrm{H}$ McCarthy, ${ }^{1} \mathrm{~L}$ Mellon, ${ }^{1} \mathrm{~F}$ Doyle, ${ }^{1} \mathrm{~F}$ Boland, ${ }^{2} \mathrm{RB}$ Reilly. ${ }^{1} \mathrm{RCS}$ Beaumont Hospital, Dublin, Ireland; ${ }^{2}$ Trinity College Dublin, Dublin, Ireland

\subsection{6/thoraxjnl-2016-209333.363}

Introduction Inhaler adherence in Chronic Obstructive Pulmonary Disease (COPD) is a crucial component of disease management with studies reporting relationships with both morbidity and mortality. The aim of this study was to identify determinants of inhaler adherence.

Methods Over a 3-year period data was collected on 265 patients with COPD whose inhaler adherence was monitored for one month. Data on personal factors (i.e., cognition, anxiety and depression), disease severity and socioeconomic factors was collected. In addition, after one month of recruitment, information on exacerbations, re-admissions, quality of life, symptoms, selfreported adherence, beliefs in medicines and psychological status were collected. Inhaler adherence was calculated as a combination of timing of use, interval between doses and technique of use (Actual Adherence).

Results At one month, patients who reported worse breathlessness (5 on the MRC Dyspnoea Scale) had worse Actual Adherence $(p=0.03)$. Interestingly, patients who had an exacerbation of their COPD within the month after recruitment had significantly lower Actual Adherence than those that didn't $(p=0.01)$. In addition, patients with poorer cognition $(p=0.02)$, poorer cough PEFR $(p<0.01)$ and more severe COPD (GOLD Stage IV, $\mathrm{p}=0.05)$ had worse Actual Adherence.

Conclusion In the large observational study of severe COPD patients, poor inhaler adherence was associated with worse symptoms, poorer cognition, more severe COPD and more exacerbations. This has significant implications for the long-term 